\title{
Codificación del derecho, interpretación de la ley y discrecionalidad judicial ${ }^{1}$
}

\author{
Law Codification, Legal Interpretation and Judicial \\ Discretion
}

Recibido: 27 de enero de 2014 - Revisado: 16 de junio de 2015 - Aceptado: 19 de octubre de 2015

Juan Carlos Martínez Salcedo

\section{Resumen}

El Código Civil francés de 1804 se erigió como la obra cumbre del movimiento de la codificación. En su elaboración, la Comisión Redactora debió dar cabida a los intereses yuxtapuestos de una sociedad francesa marcada por la diferencia y la heterogeneidad. Portalis fue el encargado de presentar ante el Consejo de Estado el proyecto de Código Civil que, si bien fue modificado durante su aprobación, sirvió como insumo necesario para la elaboración de un Discurso Preliminar que justifica la imprescindible articulación entre interpretación de la ley y discrecionalidad judicial, relación que se analiza aquí, sin perder de vista el momento en el cual ambas son propuestas y su importancia para la sistematización del derecho.

\section{Palabras clave}

Codificación, Código de Napoleón, interpretación de la ley, discrecionalidad judicial.

\section{Abstract}

The 1804 French Civil Code stands as the masterpiece of the encoding movement. In its development, the Drafting Committee had to accommodate the juxtaposed interests of a french society marked by difference and heterogeneity. Portalis was asked to submit the draft Civil Code to the State Council which, although it was modified during its approval, served as a necessary input for the elaboration of a Preliminary Speech that justifies the essential link between legal interpretation and judicial discretion, a relation discussed here, without losing sight of the moment in which both are proposed and their importance to the systematization of law.

\section{Keywords}

Codification, Napoleonic Code, legal interpretatiom, judicial discretiom.

\footnotetext{
${ }^{1}$ Este documento forma parte de la etapa preliminar de la investigación doctoral del autor, titulada "Uso de signos distintivos ajenos en la publicidad comercial", inscrita en la línea de investigación "Internet, comercio electrónico, telecomunicaciones e informática", de la Facultad de Derecho y del doctorado en Derecho de la Universidad de los Andes, Bogotá, Colombia.

${ }^{2}$ Abogado de la Universidad de la Sabana, Bogotá, Colombia, especialista en Derecho Contractual por la Universidad del Rosario, Bogotá, Colombia y magíster en Derecho Privado por la Universidad Carlos III de Madrid, Madrid, España. Profesor, Doctorando en Derecho, Facultad de Derecho de la Universidad de Los Andes, Bogotá, Colombia. Correo electrónico: jc.martinez12@uniandes.edu.co

Para citar este artículo use: Martínez, J. (2015). Codificación del derecho, interpretación de la ley y discrecionalidad judicial. Revista Civilizar Ciencias Sociales y Humanas, 15(29), 17-30.
} 


\section{Introducción}

El Discurso Preliminar al Código Civil francés, pronunciado ante el Consejo de Estado por J. M. E. Portalis, recoge los principales dogmas y fundamentos filosóficos que guiaron a la Comisión Redactora en la elaboración del proyecto que se le encargó sobre el Código Civil. El Discurso Preliminar nos presenta a un autor en el que destaca su formación jurídica que reivindica, entre otros aspectos, la estructura del conocimiento jurídico, cómo se define dentro del sistema civil, cómo se produce y cuál es el papel que le corresponde al juez al aplicar y hacer cumplir la ley.

Portalis también le da lugar al papel del derecho natural, de la naturaleza como fuente del conocimiento jurídico. Tanto es así, que en su Discurso, las referencias a las instituciones jurídicas van siendo incorporadas paulatinamente, siempre en relación con un punto de partida común: el matrimonio y la familia, así como también el rol que cumple la propiedad, a tal punto que son sus consideraciones sobre este derecho las que le permiten diferenciar y justificar aquello que es concerniente al derecho civil de lo que le pertenece al derecho mercantil (Van Roermund, 2014, p. 155).

Por tanto, en el presente documento nos proponemos hacer un estudio sobre la elaboración del derecho, los postulados del movimiento de la codificación y la necesaria interpretación de la ley, utilizando un método de investigación cualitativo. De conformidad con lo expuesto, nos centraremos en estas cuestiones, haciendo algunas menciones a los antecedentes del Código Civil, para entender el porqué de sus normas y el origen de sus instituciones; también haremos algunas alusiones a la concepción que sobre el derecho natural y sobre la razón tenía Portalis.

Para lograr este propósito, abordamos distintas fuentes doctrinales que nos han ayudado a realizar una revisión de sus propias lecturas frente a Portalis, permeadas siempre por la rama del derecho a la cual dedican principalmente sus estudios. Por eso encontraremos doctrinantes clásicos del derecho civil, del derecho penal, de la teoría jurídica y del derecho internacional.

\section{Antecedentes históricos del Código Civil de 1804}

La aparición del Código Civil de 1804 constituye un punto de inflexión en la configuración del derecho civil en una Francia revulsiva y cansada tras una larga revolución. Hasta ese momento, el derecho civil carecía de uniformidad y articulación dentro del territorio, por la coexistencia de un gran número de normas ${ }^{1} \mathrm{cu}-$ yos efectos estaban circunscritos a una determinada provincia, ciudad o aldea, que se sumaba a las diferentes fuentes de las que emanaban sus preceptos (Cruz-Ponce, 1991, p. 39).

Al Código Civil se llega tras dos periodos de evolución claramente identificables que, siendo desiguales en extensión, contribuyeron de gran manera a la construcción y a la transformación de las instituciones jurídicas que serían acogidas después por la Comisión Redactora (Carbonnier, 1960, p. 57).

El primero, reconocido como antiguo periodo, se extiende desde la Francia galorromana ${ }^{2}$ hasta la caída de la monarquía, el 14 de julio de 1789. Sus notas caracterizantes son la fragmentación territorial de sus normas, la diversidad de fuentes -devenidas del derecho romano, canónico, ordenanzas reales o costumbres $^{3}-$, la naturaleza confesional de sus instituciones, la jerarquía de las personas y de las tierras (desigualdades) y la salvaguarda de la propiedad (p. 58) .

Puesbien, enlaFrancia prerrevolucionaria, este sistema de privilegios y desigualdades que prevalecía incrementó el descontento y la reticencia popular frente al sistema jurídico. El derecho no era otra cosa que un conjunto de leyes amoldadas a las necesidades no 
incluyentes de algunos sectores privilegiados de la sociedad, que se constituían como verdaderos obstáculos de acceso y aprehensión general de los postulados normativos que legitimaban un absolutismo que rayaba en lo despótico ${ }^{5}$.

Los antecedentes descritos son la obertura del segundo periodo, conocido como derecho intermedio, que se extiende desde el inicio de la revolución hasta el Consulado ${ }^{6}$. Sus postulados provocaron un resquebrajamiento de las instituciones del derecho civil francés por su incompatibilidad con el ideario revolucionario, que defendía principios como la libertad y la igualdad (Mazeaud et al., 1959, p. 67).

Ante este panorama, era cuestión de tiempo que se estableciera un verdadero sistema jurídico como bandera de reivindicación social ${ }^{7}$. Este se estructura a partir de disposiciones alejadas del particularismo jurídico, cuya complejidad fuera reducida en tal magnitud, hasta el punto que sus disposiciones deberían acoger un modelo "simple y preciso que estuviera al alcance de la comprensión de todos los ciudadanos [...] que revelara su sentido sin necesidad de jueces y abogados" (Cremades \& Gutiérrez-Masson, 1997, p. 15).

El primer logro de la Revolución francesa, $\mathrm{y}$ una de sus principales consecuencias, fue la Declaración de los Derechos del Hombre y del Ciudadano, promulgada el 26 de agosto de 1789 , cuyos preceptos son concordantes con la Constitución francesa del 3 de septiembre de 1791, en la que ya se hacían algunas referencias al reconocimiento del imperio de la ley y la igualdad de los ciudadanos ante esta.

Dentro de los postulados de la Declaración se destaca la salvaguarda de los mencionados principios revolucionarios, reivindicando la igualdad de todos los hombres ante la ley y la libertad (de cuyas disposiciones deviene la supresión de los privilegios feudales, las distinciones nobiliarias entre los sujetos, la abolición de la esclavitud, etc.). También se consagraron principios como la seguridad jurídica y legalidad, estructurados en tres artículos, del 7 al $9^{8}$, en los que sobresale la prescripción legal para poder acusar, detener o juzgar a un ciudadano, el sometimiento de las decisiones judiciales al imperio de la ley, la necesidad y reciprocidad de la pena, la prohibición de los efectos retroactivos de la ley y la presunción de inocencia (FernándezMuñoz, 1991, p. 58).

En el ámbito del derecho civil, las aspiraciones revolucionarias debieron esperar un poco más tiempo para su concreción. Explican los hermanos Mazeaud et al. (1959) que "La orden de redactar un Código Civil, dada desde 1790 por la Asamblea Constituyente, y reiterada por la Constitución de 1791, no tuvo ningún resultado" (p. 66).

Sin embargo, durante el periodo intermedio se promulgaron algunas leyes civiles que resultaron innovadoras frente al derecho antiguo y que permitieron establecer algunas instituciones de importancia, tales como: el divorcio y la adopción en el derecho de familia; la partición sucesoral igualitaria, que se extendió a los hijos naturales; la proscripción de la jerarquía de tierras y de personas y la organización de los oficios y las corporaciones para dar lugar a la libre competencia (p. 66).

La natural evolución dio lugar a que, en julio de 1883, la Convención Nacional encargara a Cambacérès un proyecto de Código cuyo fin se dirigía a la promulgación de un verdadero sistema de derecho civil. Su fracaso se hizo notorio al ser rechazado por ser demasiado restrictivo en sus premisas. El jurista francés, acogió los comentarios hechos al primero, para presentar un nuevo proyecto a la Convención quien también lo rechazó, esta vez, por considerar muy amplio su contenido (Cremades \& Gutiérrez-Masson, 1997, p. 19).

Durante el Directorio, el mismo jurista presenta ante el Consejo de los Quinientos otro 
proyecto de Código Civil que no alcanza a discutirse. No obstante el revés de los tres proyectos de codificación, estos intentos son verdaderos antecedentes del texto de 1804 (Carbonnier, 1960, p. 60).

\section{El Código Civil de Francia}

La labor encomendada por Napoleón a la Comisión Redactora, constituida por Tronchet, Bigot de Préameneu, Malleville y Portalis, mediante el Decreto de los Cónsules del 24 termidor del año VIII -12 de agosto de 1800-, encontró un camino allanado gracias a los trabajos anteriormente discutidos, que sirvieron para decantar los objetivos que debían perseguirse con el nuevo Código (Cabrillac, 2009, p. 66).

Tras su promulgación, el 30 del ventoso del año XII -21 de marzo de 1804-, se instaura un verdadero sistema de derecho civil que consagra un cúmulo de normas referidas a un orden jurídico que se integra como un todo a la sociedad francesa. Para Carbonnier y Portalis, quien fuera, este último, designado para pronunciar el Discurso Preliminar al Código Civil francés, "tras la lectura de Montesquieu y su exilio, había captado el sentido de la relatividad y la mutabilidad y había heredado cierta predisposición a aceptar el capital postulado revolucionario de la secularización del derecho" (Carbonnier, 1960, p. 62).

Esta particular circunstancia se refleja en el memorable Discurso Preliminar al Código Civil francés, pronunciado por Portalis ante el Consejo de Estado, durante la presentación del proyecto del Código Civil. En él, el autor logra amalgamar un verdadero discurso dogmático y filosófico, que ha sido objeto de rigurosos estudios científicos desde sus inicios hasta nuestros días, que indagan sobre el verdadero alcance de sus postulados.

Por tanto, la importancia del Discurso Preliminar no se circunscribe a una mera exposición de motivos. En efecto, sus contenidos son una muestra del protagonismo que tuvo el Código Civil como instrumento jurídico de ordenación social, puesto a disposición de los ciudadanos franceses, para erradicar el poder absoluto que venía concentrándose en algunos pocos privilegiados.

En este orden de ideas, el Código Civil francés ha sido, a lo largo de la historia del derecho, una de las piezas claves y obras maestras en el establecimiento de los derechos de los ciudadanos, no solo franceses, sino del mundo entero, donde sirvió como inspiración para la promulgación de sus propios cuerpos legislativos ${ }^{9}$.

En su alocución, Portalis (1997) no solo da cuenta de la estructuración del Código, sino también de los preceptos fundamentales en torno a la significación del derecho y de las leyes para el ciudadano y para el Estado. La prudencia que se exigía de aquella Comisión Redactora se hizo patente en los postulados del Discurso, cuya necesidad era un límite infranqueable en razón de la heterogeneidad de la sociedad francesa, que era el resultado de mezclas entre diferentes pueblos, unos conquistados y otros libres (p. 28).

Reconocer la diferencia de la sociedad francesa era un axioma imprescindible para la posterior aceptación de su obligatoriedad y observancia. Portalis (1997) tenía presente que los distintos pueblos que convergían en Francia abogaban por la salvaguarda y permanencia de sus propias normas, dejando claro que "la experiencia demuestra que los hombres cambian más fácilmente de dominación que de leyes" (p. 28).

Con base en lo anterior, pareciera que se estuviera intercediendo por mantener la fuerza vinculante de las leyes y ordenanzas que rigen a una sociedad, cuando dichas normas son percibidas como obligatorias y legítimas por el ciudadano. Incluso si su sistema de gobierno ha sido modificado o si dicha sociedad se 
encuentra bajo el influjo de distintos regímenes jurídicos.

Este parecer halla sentido en el Discurso de Portalis (1997), para quien las leyes no son meros actos de poder, sino todo lo contrario, "actos de prudencia, justicia y razón" (p. 32). Todo parecería indicar que la Comisión Redactora procura un derecho cuyo fundamento sea la razón ${ }^{10}$, pues solo así se lograría una correcta integración de aquella sociedad desagregada en naciones y pueblos que, por igual, buscan la defensa de sus propios postulados ${ }^{11}$.

Estas razones son las que justifican que el Código Civil admita como insumos para la elaboración de sus postulados a les coutumes, el derecho romano, las ordenanzas reales y las leyes de la revolución ${ }^{12}$. Por tanto, que las instituciones jurídicas acogidas por la Comisión Redactora encuentren sus antecedentes en diferentes escenarios jurídicos, da cuenta de que el Código es el producto de un proceso evolutivo del derecho civil francés ${ }^{13}$, que responde adecuadamente a las necesidades de su propio tiempo (CastanTobeñas, 1957, p. 29).

Planiol y Ripert (1981) defienden las bondades del Código y su acomodación a los propósitos y necesidades de la sociedad francesa, lograda por la moderación y la prudencia de sus redactores:

Tuvo la buena fortuna de ser hecho en un momento excepcionalmente favorable para una redacción equitativa de las leyes civiles. Ello le dio su cualidad dominante, el espíritu de moderación y de prudencia que ha asegurado su duración. [...] Es una ley de transacción. Ha salido de la Revolución y ha respetado el espíritu igualitario, pero al mismo tiempo ha abandonado todas las ideas quiméricas, todas las medidas violentas de la Asamblea de la Revolución; no es reaccionista (p. 35).

Colin y Capitant (2002) coinciden con Planiol y Ripert al defender los provechos del Código:
La ley hecha para la generalidad de los hombres debe corresponderse también al término medio en las ideas y opiniones. No debía aspirar a crear costumbres sino a reflejarlas. Y de aquí que el Código hecho para una sociedad fatigada por los excesos y utopía de la Revolución respondió de la manera más adecuada a las aspiraciones de su tiempo (p. 62; cursiva del autor).

Por ende, el mayor logro de la Comisión Redactora no fue otro que admitir la diferencia como paladín de moderación. Esto le permitió construir un proyecto de Código Civil que tendría como propósito consolidarse como una norma de derecho civil adaptada a las necesidades puntuales de los ciudadanos a los cuales se dirigía.

En cuanto a su estructura, el proyecto del Código Civil que se expuso ante el Consejo de Estado estaba organizado en tres libros, antecedidos por un título preliminar: "Del derecho y de las leyes". En estas disposiciones se recogían aquellos preceptos filosóficos y dogmáticos que estuvieron siempre presentes durante su elaboración. No obstante, al contrastar el proyecto con el texto definitivo de 1804 , se puede verificar que muchos de aquellos postulados fueron suprimidos durante su etapa de aprobación. Carbonnier (1960) justifica esta supresión, "no por disconformidad doctrinal sino por el hecho de que un cuerpo codificado no es lugar apto para su emplazamiento" (p. 13).

Así las cosas, las disposiciones que se eliminaron del proyecto de Código, tuvieron un lugar en el Discurso Preliminar de Portalis, constituyéndose en un criterio informador e interpretativo que permite conectar armónicamente las partes que daban vida al Código Civil. Por tal razón, aquellas premisas fundamentales, vigentes aun en los tiempos que corren, sobre la irretroactividad de la ley, la seguridad jurídica, el orden público, la igualdad ante la ley, entre otras, deben ser objeto de observación cuidadosa por el operador jurídico al aplicar el derecho al caso específico. 
$\mathrm{Y}$ es que las cosas no podrían ser de otra manera, pues se trataba de un Código que, en tanto ley, es vinculante para todo el conglomerado social, que "considera a los hombres en masa, nunca como particulares, no debe ocuparse de los hechos individuales ni de los litigios -concretos- que separan a los ciudadanos" (Portalis, 1997, p. 44).

Por ello, no puede distinguir la ley al sujeto al que se aplica, resultando vinculante para todos los ciudadanos, sin distinción entre los hombres (hombres, niños, mujeres y ancianos) ${ }^{14}$ e incluso, comprende a los extranjeros que se encuentren en el territorio, siendo esta vinculación la que supone el sometimiento a la soberanía del Estado (Ferrante, 2013, p. 31).

Hacer efectiva la obligatoriedad de la ley implica su previo conocimiento, lo cual exige que las disposiciones normativas se den a conocer al conglomerado social mediante algún mecanismo idóneo a tal fin. Por ende, una vez hechas públicas, las obligaciones impuestas por el soberano cobran plenos efectos hacia futuro, ligando a todos los asociados desde ese mismo instante, proscribiendo del ordenamiento jurídico su aplicación retroactiva por considerarse perjudicial para el ciudadano.

\section{Los procesos de codificación frente a la interpretación judicial del derecho}

Los procesos de codificación ${ }^{15}$ abogaban por otorgar al derecho un orden técnico y sistemático, que abandonara la fragmentación normativa para dar paso al reconocimiento de la ley positiva como única -o al menos, como principal- fuente del derecho, que le permita dar respuestas armónicas y justas a la sociedad.

En tal sentido, los procesos de codificación modifican "radicalmente el papel tradicional asignado al jurista, redimensionándolo y prácticamente devaluándolo. El antiguo intérprete se transforma en un simple exégeta, en principio solo debe explicar las normas del Código y atenerse pasivamente a lo que estas prevén" (Caroni, 2013, p. 59). Esta concepción no es otra cosa que el reconocimiento de plenitud del movimiento codificador, en el que "el Código llega a comprender todo el derecho: el pasado, recogiendo todo el derecho nacional, el entonces presente, y el futuro, previendo hasta sus propios cambios y posibles lagunas" (Narváez, 2012, p. 156).

Por ende, el concepto de Código debe necesariamente asociarse al de plenitud, al reconocerse como completo, sistemático, unívoco y autónomo: esto implica que sus postulados no admiten interpretaciones; y si bien, acepta la existencia de fuentes subsidiarias, estas solo pueden tener cabida en la medida en que no pongan en tela de juicio su supremacía (Caroni, 2013, p. 30).

La codificación es la tipificación de las conductas sociales que han de regularse, dejando al jurista solo un espacio de mera adecuación de la ley al caso sub examine, sin que tenga cabida algún ejercicio hermenéutico, a tal punto que las zonas grises del derecho, deben mantenerse como tal o remitirse al legislador para que allí se acoja la solución particular.

Estos postulados tan radicales que caracterizan a la codificación no están presentes en el Discurso Preliminar, en el que, por el contrario, Portalis reconoce la imposibilidad en cabeza del legislador para acoger en la norma todas las situaciones sociales posibles $\mathrm{y}$ otorgarles a cada concreto una solución particular ${ }^{16}$. Esta es la razón para contemplar en la ley descripciones generales que contengan principios normativos desde donde el operador judicial pueda descender las respuestas jurídicas de aquellos casos específicos, lo que supone consentir la posibilidad de interpretar el derecho a partir del espíritu del legislador.

Hernández-Jiménez (2014) reconoce como causa de la disonancia entre los postulados del movimiento de la codificación y el Discurso 
Preliminar la supresión que hiciera el Consejo de Estado del artículo 9 del texto definitivo del Código Civil. Este artículo

[...] habilitaba el juicio de equidad frente a la existencia de lagunas normativas, razón por la cual la exégesis se limitó a la utilización del artículo 4 del mismo compendio, que exigía la aplicación de la ley, so pena de incurrir en denegación de justicia (p. 142).

Aunado a lo anterior, Portalis, en tanto jurista que era, observaba las dificultades y las limitaciones que debía afrontar la magistratura para impartir justicia, durante los tiempos que antecedieron al Código Civil. Es pertinente traer a colación que las facultades interpretativas de los jueces habían sido coartadas con fundamento en un decreto orgánico del 16/24 de agosto de 1790, que imponía al operador judicial la obligación de remitir al legislativo las cuestiones dudosas o ambiguas contenidas en la ley cuando estas debían aplicarse al caso sub judice ${ }^{17}$.

Con ello, el juez carecía de las facultades interpretativas necesarias para adecuar la norma al caso concreto, más aún, debía dilatar la resolución del conflicto hasta tanto el legislador no hubiere abordado la cuestión remitida $\mathrm{y}$, además, el litigio debía zanjarse con base en disposiciones hechas a posteriori para el caso específico.

Portalis (1997) en su Discurso manifiesta su rechazo abierto a la coartación del papel del juez en la aplicación del derecho, pues esto solo puede ser causa de mayor inseguridad jurídica. Estas podrían ser las razones que llevaron a dos tipos de ciencias claramente definidas, la ciencia del legislador y la ciencia del juez. La obligación del primero es buscar siempre los principios más favorables al bien común, a través de una norma positiva, de carácter general y abstracto, que sirve al magistrado para esclarecer aquellas situaciones que puedan presentarse en la convivencia social. A su vez, la segunda ciencia gobierna al magistrado, quien durante la aplicación de esos principios, de una manera sabia y razonada, deberá aplicar la ley a los casos precisos.

[...] la misión de la ley es fijar a grandes rasgos las máximas generales del derecho, establecer los principios fecundos en consecuencias y no descender al detalle de las cuestiones que pueden surgir en cada materia, [así pues, le corresponde] al magistrado y al jurisconsulto, penetrados del espíritu general de las leyes, [...] dirigir su aplicación (p. 36).

El rol de Portalis no solo destaca ante la necesidad de reconocer estas dificultades que rodearon su encargo ${ }^{18}$, también lo hace por intentar ofrecer verdaderas respuestas a semejantes pretensiones. Si el Discurso es visto desde esta perspectiva, se puede colegir que su retórica justifica apropiadamente el papel del magistrado. En este orden de ideas, un adecuado sistema de derecho civil es "el mayor bien que los hombres pueden dar y recibir; son la fuente de las costumbres, el palladium de la propiedad y la garantía de toda paz pública y particular" (p. 31), siendo requisitos sine qua non, el otorgarle un papel protagónico idóneo, y no mayor al que realmente debe ostentar el derecho civil, como instrumento de moderación del poder desde su observación y acogida y no el de fundar y mantener un gobierno.

Para lograr el propósito es necesario acudir al juez. Justamente corresponde al magistrado, mantener y abogar por el verdadero rol del derecho civil: es que, como explica Hervada (2000), la función del jurista no puede ser otra que el discernimiento y la determinación de lo justo -del derecho- en los casos concretos, labor asignada al juez, quien es aquel que determina y ordena con autoridad lo debido en el caso específico (p. 72).

Portalis (1997) admitió ese papel innegable del juez en el Código Civil. Y lo hace, a partir de la estaticidad de la ley frente al derecho, que es dinámico, no pudiendo ser otro sujeto más que el magistrado, "la voz del 
derecho", quien debe encargarse de imprimirle dicho dinamismo. Y es que es así, sin que pueda ser de otra manera, porque "el oficio de la ley es fijar, con amplitud de miras, las máximas generales del derecho, establecer principios fecundos y consecuencias, y no el de descender al detalle de las cuestiones que puedan nacer sobre cada materia" (p. 36).

Es lo precedente la causa que legitima el oficio del jurista. Un operador jurídico que debe reconocer el espíritu de la ley, para luego sí, dar aplicación efectiva de esta al caso concreto en procura de lo que es debido a cada quien; por tanto, corresponde al magistrado un verdadero ejercicio de razonamiento práctico en orden a la adjudicación del derecho concreto, en el que han de integrarse elementos racionales que van más allá del mero razonamiento subsuntivo (Suárez-Rodríguez, 2010).

Es pertinente aceptar en el jurista el papel fundante del derecho -la jurisprudencia es verdadera fuente de derecho-, que no puede confundirse con la elaboración formal, propiamente dicha, de la ley. El legislador se vale de la sociología jurídica para identificar las cuestiones que han de ser reguladas, pero es el juez, quien lleva al caso práctico la situación tipificada, y la califica a la luz del precepto normativo. Sin embargo, no puede olvidarse que en la labor hermenéutica, el juez es proclive a una indebida aplicación de la ley, en tanto resultado de un proceso deductivo, en dichos casos, la integridad del derecho (como sistema) protege al administrado, pues el juez no tiene potestad para despegarse del imperio de la ley. Para Portalis (1997) "las cuestiones que se le ofrecen no le permiten olvidar jamás que, si hay cosas que quedan al arbitrio de su razón, no las hay que queden puramente al de su capricho o voluntad" (p. 39).

Expuesto lo anterior, ha quedado patente la certeza que tenía Portalis de la imposibilidad de reconocer al Código como norma única y completa del derecho civil, pues ninguna norma positiva podía ser "completa y omnicomprensiva; toda ley -por claro que fuera su texto-debía ser interpretada por el jurisconsulto para darle una aplicación concreta y específica" (ZelayaEtchegaray, 1991, p. 261).

Así las cosas, en Portalis (1997) bien puede reconocerse dos tipos de interpretación, una por vía de doctrina y otra por vía de autoridad, estando el primero permitido y el segundo prohibido para el juez. Mientras la doctrina busca "captar el verdadero sentido de las leyes, en aplicarlas con discernimiento y en suplirlas en los casos que no han regulado" la autoridad solo puede "resolver las preguntas y las dudas por vía de reglamentos o de disposiciones generales" (p. 42).

\section{El favorecimiento de la seguridad jurídica y del principio de legalidad a partir de la interpretación judicial}

La seguridad jurídica es un dogma del derecho, cuyo fundamento es la consagración positiva de la ley, aquella "situación peculiar de un individuo como sujeto activo y pasivo de relaciones sociales cuando estas relaciones se hallan previstas en un estatuto objetivo, conocido y generalmente observado" (MillasJímenez, 1961, p. 238).

Este principio propende por la certeza -como estado del conocimiento- que tiene el sujeto de derechos respecto de las cuestiones que le son prohibidas, que le son permitidas o que le son obligatorias. Esta certeza es consecuencia de un argumento de autoridad de quien ostenta el poder legislativo, lo cual permite suponer que cualquier modificación incoada sobre el sistema jurídico estará sometida a procedimientos predeterminados, de manera previa y clara por el derecho. La seguridad jurídica se manifiesta a través del principio de legalidad, que ha de ser entendido como:

[...] el fundamento jurídico en virtud del cual los ciudadanos y todos los poderes públicos 
están sometidos a las leyes y al derecho [...] implica el fundamento o la base que resguarda a todos los ciudadanos para que se respeten sus derechos y se impongan sanciones solo por las conductas que el legislador haya calificado como punibles y que al ser delito conllevan una pena, ante el incumplimiento de las obligaciones que los rige (Orduz-Barreto, 2010, p. 103).

Los postulados de la seguridad jurídica y el principio de legalidad salvaguardan el imperio de la ley, cuyo objeto es definido por el legislador, desde la consagración de principios que propendan por el interés general y el bien social; es indiscutible que debe ser el juez el encargado de adecuar dichos principios a los casos concretos, pero, según plantea Portalis (1997), el poder judicial "necesita ser dirigido, en esa aplicación, por ciertas reglas [...] que nunca pueda la razón de ningún hombre prevalecer sobre la ley, razón pública" (p. 50).

Al reconocerse los linderos observables por el juez, sus decisiones deben estimarse como instrumentos de dinamización del derecho, en cuyo texto se compilan "usos, máximas y reglas" con un propósito claro: la homogeneización en la aplicación del derecho; que el caso particular sea juzgado a partir de las mismas consideraciones y dentro de los mismos preceptos respecto de otros análogos, aun tratándose de casos difíciles. Al respecto Portalis (1997) expone que:

Se reprocha a quienes profesan la jurisprudencia haber multiplicado las sutilezas, las complicaciones (de cuestiones, controversias y resoluciones) y los comentarios. Este reproche puede ser fundado. Pero, ¿en qué ciencia no se está expuesto a merecerlo? ¿Debe acusarse a una clase particular de hombres de lo que no es más que una enfermedad general del espíritu? (p. 37).

Con estos preceptos, ya no le es dable al juez negarse a resolver casos difíciles (y con ellos, verse abocado a un supuesto de denegación de justicia), tampoco el remitir al legislador para que acoja una solución sobre el particular (invadiendo la esfera judicial), pues justamente, dichos casos han de resolverse a partir de, ahora sí, un ejercicio de razonamiento práctico-prudencial que concluye con un acto de adjudicación del derecho.

Si en algo puede perdonarse la intemperancia en comentar y discutir es en la jurisprudencia. No se vacilará en creerlo, si se reflexiona en los innumerables hilos que llegan a los ciudadanos, sobre el desarrollo y la progresión sucesiva de las materias de que el magistrado y el jurisconsulto están obligados a ocuparse, sobre el curso de los acontecimientos y las circunstancias que de tantas maneras modifican las relaciones sociales, sobre la acción y la reacción continua, en fin, de todas las pasiones y los diversos intereses. Ese que censura las sutilezas y los comentarios, se convierte, en una causa propia, en el comentarista más sutil y fastidioso (Portalis, 1997, p. 37; cursivas hechas por el autor).

Por tanto, seguridad jurídica y principio de legalidad no pueden, según Portalis, estimarse como sometimiento exclusivo del juez a la ley. La norma es un límite infranqueable, pero es solo eso, un límite dentro del cual el derecho, en tanto sistema, en tanto todo, permite discurrir en su espíritu, en la costumbre, la equidad (como ley natural), para coadyuvar en la concreción de la justicia en el caso contradictorio y gris, pareciendo confirmar la ya mencionada "leyenda negra" con la que ha sido categorizada la Escuela de la Exégesis (Botero-Bernal, 2015).

\section{Conclusiones}

Es indudable la importancia de Portalis y de sus aportaciones al Código Civil francés de 1804. Un Código permeado por instituciones jurídicas que aún siguen vigentes y tienen la misma trascendencia desde cuando vieron la luz, y es que en definitiva, lo antiguo también fue nuevo alguna vez.

En su obra, encontramos un estudio claro y novedoso respecto de la interpretación del 
derecho y el conocimiento científico del derecho. Si bien es cierto que sus postulados están amalgamados con el iusnaturalismo de la época, acogidos por un positivismo motivado por la diferencia de la sociedad francesa, reconocida en el establecimiento de distintas naciones que comparten un territorio.

Portalis, como miembro de la Comisión Redactora, abogó por un código que resultara compatible con el derecho antiguo y el derecho intermedio, acogiendo desde diferentes orígenes, instituciones que resultaran aplicables a las necesidades sociales del momento, salvaguardando los principios revolucionarios de libertad, igualdad y fraternidad.

Y es que esto era menester, dada la fragmentación de la sociedad francesa, construida a partir de la unión de pueblos libres y conquistados, que se reconocían como verdaderas naciones, todas ellas, confluyendo en un único Estado, el francés, que por tanto, debía garantizar sus intereses, de un modo homogéneo.

Estos retos particulares estaban presentes en la elaboración del Código Civil, una obra que termina proclamándose como el preludio del movimiento de la codificación, cuyos preceptos están dirigidos a regir al Código como norma única, suprema, completa y autónoma, que no admite interpretación, solo su aplicación al caso concreto.

Sin embargo, Portalis, sabio jurista, era consciente de que lo que se pretendía de dicha norma resultaba imposible, pues el derecho escrito es estático mientras que la sociedad es dinámica. Por ello, sus postulados debían cobrar movimiento, cuestión que solo era viable al admitirse que el Código, aun cuando fuente primaria, debía acompañarse de otras secundarias respecto de las cuales, magistrado y jurisconsulto, deben realizar un verdadero proceso interpretativo que permita su aplicación al caso concreto.

Así las cosas, la codificación en Portalis no limita la aplicación del derecho a una mera exégesis del Código, sino que admite una verdadera y efectiva interpretación. Si bien es cierto que la exégesis ha sido presentada como una teoría que niega por completo la discrecionalidad judicial, luego de un detallado estudio del Discurso Preliminar, hemos de llegar a otro lugar, aquel en el que, en sus orígenes, permite vislumbrar cierta cercanía con el iusnaturalismo racionalista, aun cuando con posterioridad, cobrarían relevancia autores mucho más radicales, que buscaron apartarse por completo, para posicionarse en la orilla del positivismo legalista, tal cual hoy lo conocemos.

\section{Notas}

${ }^{1}$ Laurent citado por Cruz-Ponce (1991, p. 40), da cuenta de la existencia de sesenta sistemas de derecho civil de índole general que pertenecían a una provincia- y trescientos de índole local -que solo eran obligatorios en una ciudad, villa o aldea determinada-.

${ }^{2}$ Antecediendo incluso a las invasiones bárbaras del siglo II, los hermanos Mazeaud reivindican el edicto del emperador Caracalla, de 212, como aquel que permite la integración del derecho galorromana (Mazeaud, Mazeaud, \& Mazeaud, 1959, p. 56).

${ }^{3}$ Colin y Capitant (2002) explican que "el derecho de la monarquía francesa en vísperas de la revolución no era uniforme [...]. El reino se dividía en dos regiones, que correspondía en su extensión, poco más o menos, al norte y al mediodía, los países de costumbres y los países de derecho escrito" (p. 10).

${ }^{4}$ No es pretensión de este artículo hacer un estudio profundo de la evolución del derecho francés desde el pluralismo del bajo medioevo hasta la edad moderna, cuya cúspide tuvo lugar con la expedición del Código Civil de 1804. Al respecto, sugerimos acudir al documento Del mito y de la razón en la historia del pensamiento político, de García-Pelayo (1968). 
5 López-Oliva (2011) expone que "El despotismo, es un régimen que no reconoce ni obedece las leyes y menos si no le convienen; es más, las leyes son estructuradas por el régimen monárquico en este caso, de acuerdo a sus conveniencias; el despotismo limita y dificulta la consagración del principio de Seguridad Jurídica y 'el desarrollo de la soberana potestad pública'” (p. 124).

${ }^{6}$ El Consulado fue una forma de gobierno que reemplazó al Directorio, que va desde el 18 de brumario de 1799 hasta 1804 cuando Napoleón Bonaparte es designado emperador (Norvins, 1846, p. 256).

${ }^{7}$ Leclair (2002) se preguntaba por las razones que pudieran explicar el por qué un código que ha de ser catalogado como revolucionario podía, sin embargo, reivindicar el conservadurismo, la tradición y la autoridad. La respuesta la encontró, en gran medida, en el contexto social, político y económico de la Francia de 1800 y que desarrolla en su escrito Le Code Civil des Français de 1804: une transaction entre révolution et réaction (p. 46).

8 El artículo 7 de la Declaración de los Derechos del Hombre y del Ciudadano, consigna que "Ninguna persona puede ser acusada, detenida y encarcelada, sino en los casos determinados por la ley, según las formas prescritas en ella. Los que solicitan, facilitan, ejecutan o hacen ejecutar órdenes arbitrarias, deben ser castigados; pero todo ciudadano llamado o requerido en virtud de lo establecido en la ley, debe obedecer inmediatamente: se hace culpable por la resistencia".

${ }^{9}$ La influencia del Código de 1804 ha sido afirmada por grandes doctrinantes. Petit (2008) reconoce que las primeras traducciones al español del Code "carecieron de intención jurídica (la vía de publicación contribuyó además al efecto), más su mera existencia documenta el pago del tributo debido a la supremacía lingüística francesa"; para luego anotar que el Code "había aportado desde los tiempos humildes de su vida en las gacetas un completo 'vocabulario y un repertorio de fórmulas protocolarias' que, con independencia de proyectos nacionales y traducciones más o menos directas, fue el idioma exquisito que muy pronto hablaron las clases jurídicas. Un derecho civil de individuos propietarios que trafican con sus bienes y viven bajo la disciplina (paterna y estatal) de la unidad doméstica, destilado en breves proposiciones legales con numeración corrida" (p. 1775); en este sentido, consúltese Botero-Bernal (2015).

${ }_{10}$ Portalis (1997) reconoce el cimiento del derecho en la razón universal y no en la obediencia al soberano, como plantean los contractualistas. Aunque la razón en Portalis pareciera estar condicionada por el derecho natural: "El derecho es la razón universal, suprema razón fundada en la naturaleza misma de las cosas. Las leyes son o solo deben ser el derecho reducido a reglas positivas, a preceptos particulares" (p. 46).

${ }^{11}$ De la Escuela de la Exégesis, que tuvo lugar ente 1804 y 1880, se ha dicho a lo largo de la historia que es legalista; sin embargo, algunos autores han venido reivindicando una visión renovada de la historia del derecho, en la que se aboga por una exégesis diferente, que se acerca al iusnaturalismo racionalista. En tal sentido, Hespanha (2012) atribuye como causa de tal acusación, a una "leyenda negra" que nació del libro L'ecole de l'exégèse en droit civil, de Bonnecase (1919), en el que, dada la situación del momento, "el juicio sobre el legalismo y sobre la Escuela de la Exégesis ganaba un significado político" que permitía la coexistencia ideológica entre quienes intercedían por un nuevo orden y los que lo hacían por un Estado democrático (pp. 44-45).

12 Las costumbres le aportaron al Código algunas instituciones referidas a la incapacidad de la mujer casada, la potestad marital, la comunidad de bienes entre cónyuges 
y algunas reglas sobre sucesiones; el derecho romano aportó instituciones jurídicas sobre el régimen de propiedad, el de obligaciones y contratos y el régimen dotal; de las ordenanzas reales devienen algunas instituciones sobre el estado civil, las donaciones, testamentos y restituciones; finalmente, de las leyes de la Revolución se acogen instituciones sobre la mayoría de edad, el matrimonio y el régimen hipotecario (Castan-Tobeñas, 1957, p. 28).

${ }^{13} \mathrm{Si}$ bien es cierto que el derecho reconocía la existencia de instrumentos privilegiados empleados para ejercereldominioy propenderpor la unificación de los territorios, es innegable que el Código Civil, en tanto fruto del discernimiento de ilustres juristas, "logró una síntesis entre las viejas costumbres y los nuevos principios, símbolo de la nueva sociedad y encarnación de la modernidad a través de la igualdad civil, la laicización y la defensa de la propiedad. [...] caracterizado por una concepción unitaria del derecho y como 'ley natural positivada' y ahistórica" (Besabe-Martínez, 2010, p. 58), así se evidencia en el Discurso de Portalis, y en los postulados por él defendidos.

14 Ferrante (2013) da cuenta de la concepción liberal del Código francés, al observar el principio de igualdad que determina "la unidad del sujeto del derecho, representado en el ciudadano francés, y no ya -de caso en caso- por el nombre, o el eclesiástico, o el burgués, a cada uno de los cuales hacían referencia disciplinas civilistas diferentes" (p. 59).

${ }^{15}$ El movimiento codificador, considerado el antecedente más próximo del positivismo jurídico, se consolida con la promulgación del Código Civil francés, su texto cumbre, precedido por el Código prusiano de 1794 y subseguido por el Código austriaco de 1811 (Hernández-Jiménez, 2014, p. 141).

16 Para Portalis (1997), mientras la sociedad es dinámica, la ley es estática, por tal razón, "un código, por muy completo que pueda parecer, apenas está acabado cuando miles de cuestiones inesperadas se le ofrecen al magistrado. Pues las leyes, una vez redactadas, permanecen tal como han sido escritas. Los hombres por el contrario, no descansan nunca; siempre actúan" (p. 36).

${ }^{17}$ El temor a la innovación judicial nació con anterioridad a la misma codificación: por decreto orgánico del 12/24 de agosto de 1790 se reservó en la Asamblea Legislativa no solo el derecho de dictar disposiciones de índole general sino también el de interpretar la ley (tít. II, art. 12). Apareció así la institución del référé legislativo para remitir en consulta (imperativa) al Tribunal de Casación, los casos dudosos que no podían cubrirse mediante la ley (Menicocci, 1992, p. 39).

18 Reiteramos aquí que, hacia 1804, los territorios conquistados por el imperio francés dejaban constancia de la diversidad de naciones (culturas, costumbres, religiones $\mathrm{y}$ ascendencias) que cohabitaban en un mismo territorio (exceptuándose a los territorios de colonias), respecto del cual se pretendía establecer un único sistema jurídico civil, en el que tuvieran cabida todos los pueblos. Así, el riesgo latente de caer en el establecimiento de normas que no reconocieran la diferencia, era una preocupación en quienes fueron encargados de redactar el Código Civil.

\section{Referencias}

Besabe-Martínez, N. (2010). Del imperio a la federación: La idea de Europa en Francia, 1800-1848 (Tesis Doctoral). Universidad Complutense de Madrid, España.

Botero-Bernal, A. (2015). El positivismo jurídico en la historia: las escuelas del positivismo jurídico en el siglo XIX y primera mitad del siglo XX. En J. L. Zafra-Zamorano \& A. Nuñez-Vaquero (Eds.), Enciclopedia de filosofia y teoría del derecho (Vol. 1, pp. 63-170). Mexico: Universidad Nacional Autónoma de Mexico. 
Cabrillac, R. (2009). French private law since the napoleon code. Revista de Derecho, 22(2), 65-73.

Carbonnier, J. (1960). Derecho Civil (Trad. M. Zorrilla Ruiz, Vol. 1). Barcelona: Bosch.

Caroni, P. (2013). Lecciones de historia de la codificación (Trads. A. Mora Cañada \& M. Martínez Neira). Madrid: Universidad Carlos III de Madrid.

Castan-Tobeñas, J. (1957). Los sistemas jurídicos contemporaneos del mundo occidental (2da ed.). Madrid: Instituto Editorial Reus.

Colin, A., \& Capitant, H. (2002). Derecho Civil. Introducción, personas, estado civil, incapaces (Vol. 1). Mexico D. F.: Editorial Jurídica Universitaria.

Cremades, I., \& Gutiérrez-Masson, L. (1997). El proyecto de un código civil y la revolución. Discurso preliminar al Código Civil Francés. Madrid: Editorial Civitas S. A.

Cruz-Ponce, L. (1991). El Código Civil francés. En Instituto de Investigaciones Jurídicas. (Ed.), Bicentenario de la revolución francesa (pp. 39-46). Mexico D. F.: Universidad Nacional Autónoma de México.

Fernández-Muñoz, D. E. (1991). Las repercusiones de la Revolución francesa en el área del derecho penal. En Instituto de Investigaciones Jurídicas (Ed.), Bicentenario de la Revolución Francesa (pp. 47-58). Mexico D. F.: Universidad Nacional Autónoma de México.

Ferrante, R. (2013). Los orígenes del modelo de codificación entre los siglos XIX y XX en Europa, con particular atención al caso italiano, Revista de Derecho Privado, 25, 29-53.
García-Pelayo, M. (1968). Del mito y de la razón en la historia del pensamiento político. Madrid: Editorial Revista de Occidente.

Hernández-Jiménez, N. (2014). Poder soberano y poder disciplinario. La codificación desde una visión foucaultiana. Revista de Estudios Sociales, 48, 139-150. doi:10.7440/res48.2014.11

Hervada, J. (2000). Lecciones propedéuticas de filosofía del derecho. Pamplona: EUNSA.

Hespanha, A. M. (2012). Tomando la historia en serio. Los exégetas según ellos mismos. Revista Forum, 2(3), 13-51.

Leclair, J. (2002). Le Code Civil Des Français de 1804: Une Transaction entre révolution et réaction. Revue Juridique Thémis, 36. Recuperado de https://papyrus. bib.umontreal.ca/xmlui/bitstream/handle/1866/1429/Code\%20civil\%20des\%20 Fran\%C3\%A7ais\%20de\%201804.pdf

López-Oliva, J. O. (2011). La consagración del principio de seguridad jurídica como consecuencia de la revolución francesa de 1789. Prolegómenos Derecho y Valores, 14 (28), 121-134.

Mazeaud, H., Mazeaud, L., \& Mazeaud, J. (1959). Lecciones de Derecho Civil (Trad. L. Alcalá-Zamora, Vol. 1). Buenos Aires: Ediciones Jurídicas Europa-America.

Menicocci, A. (1992). Notas sobre "Metodos de interpretación y fuentes en derecho privado positivo", de François Geny. Investigación y Docencia, 15, 37-44.

Millas-Jímenez, J.(1961). Filosofia del Derecho. Santiago: Editorial Universitaria.

Narvaez, J. R. (2012). El Código Civil en México: entre la forma y la tradición. Precendentes, 1, 149-178. 
Norvins, J. M. (1846). Historia de la Revolución Francesa, del consulado, del imperio y de las dos restauraciones hasta la caída de Carlos X (Vol. I). Barcelona: Imprenta y Libreria de la viuda e hijos de Mayol.

Orduz-Barreto, C. (2010). El principio de legalidad en la ley penal colombiana. Criterio jurídico garantista, 2 (2), 100-107.

Petit, C. (2008). España y el Code Napoleón. Actas de Derecho Civil, 6(4), 1773-1840.

Planiol, M., \& Ripert, G. (1981). Tratado elemental de derecho civil (Trad. J. M. Cajica). Cardenas Editor y Distribuidor.

Portalis, J. E. M. (1997). Discurso Preliminar al Código Civil Francés. (Trads. I. Cremades \& L. Gutiérrez-Masson). Madrid: Editorial Civitas S.A.

República Francesa. Declaración de los Derechos del Hombre y del Ciudadano (26 de agosto de 1789). Asamblea Nacional
Francesa. Recuperado de http://www.juridicas.unam.mx/publica/librev/rev/derhum/cont/30/pr/pr23.pdf

República Francesa. Ley del 21 de marzo de 1804. Código Civil de los Franceses.

Suárez-Rodríguez, J. J. (2010). La determinatio en el proceso de adjudicación: una visión prudencial del razonamiento jurídico. Díkaion, 19(2). Recuperado de http:// dikaion.unisabana.edu.co/index.php/ dikaion/article/view/1785/2393

Van Roermund, B. (2014). The code civil between enlightenment and restoration. The heritage of portalis. Diametros: An Online Journal of Philosophy, 40, 149175. doi:10.13153/diam.40.2014.634

Zelaya-Etchegaray, P. (1991). Portalis y el sentido del texto (sobre la interpretación de la Ley). Revista Chilena de Historia del Derecho, 14, 259-266. doi: 10.5354/07195451.1991 .24833 